\title{
Correction to: Habitat morphology and connectivity better predict hydrophyte and wetland plant richness than land- use intensity in overexploited watersheds: evidence from the Po plain (northern Italy)
}

\author{
R. Bolpagni $(\mathbb{D} \cdot$ A. Laini $\cdot$ F. Buldrini - G. Ziccardi E. Soana • \\ G. Pezzi - A. Chiarucci - E. Lipreri $\cdot$ S. Armiraglio · J. Nascimbene
}

Published online: 21 September 2021

(C) Springer Nature B.V. 2021

Correction to: Landscape Ecol (2020) 35:1827-1839 https://doi.org/10.1007/s10980-020-01060-2

In the original publication of the article the 8th author name was misspelt and now the correct name is provided in this correction and the original article has been corrected.

Publisher's Note Springer Nature remains neutral with regard to jurisdictional claims in published maps and institutional affiliations.

The original article can be found online at https:// doi.org/10.1007/s10980-020-01060-2.

R. Bolpagni $(\bowtie) \cdot$ A. Laini

Department of Chemistry, Life Sciences and Environmental Sustainability, Parma University, Parco Area delle Scienze 11/a, 43124 Parma, Italy

e-mail: rossano.bolpagni@unipr.it

F. Buldrini - G. Ziccardi · G. Pezzi .

A. Chiarucci - J. Nascimbene

Department of Biological, Geological and Environmental Sciences, University of Bologna Alma Mater Studiorum,

Via Irnerio 42, 40126 Bologna, Italy

E. Soana

Department of Life Sciences and Biotechnology,

University of Ferrara, Via L. Borsari 46, 44121 Ferrara, Italy

E. Lipreri · S. Armiraglio

Natural Science Museum, Via Antonio Federico Ozanam, 25128 Brescia, Italy 